\title{
N. Le Roux, Les guerres de religion
}

\section{Michele Mastroianni}

\section{(2) OpenEdition}

\section{Journals}

\section{Edizione digitale}

URL: http://journals.openedition.org/studifrancesi/9916

DOI: 10.4000/studifrancesi.9916

ISSN: 2421-5856

\section{Editore}

Rosenberg \& Sellier

\section{Edizione cartacea}

Data di pubblicazione: 1 août 2017

Paginazione: 346

ISSN: 0039-2944

\section{Notizia bibliografica digitale}

Michele Mastroianni, «N. Le Roux, Les guerres de religion», Studi Francesi [Online], 182 (LXI | II) | 2017

online dal 01 août 2017, consultato il 06 janvier 2021. URL: http://journals.openedition.org/

studifrancesi/9916 ; DOI: https://doi.org/10.4000/studifrancesi.9916

\section{Questo documento è stato generato automaticamente il 6 janvier 2021.}

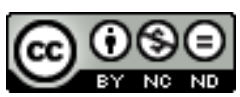

Studi Francesi è distribuita con Licenza Creative Commons Attribuzione - Non commerciale - Non opere derivate 4.0 Internazionale. 


\title{
N. Le Roux, Les guerres de religion
}

\author{
Michele Mastroianni
}

\section{NOTIZIA}

NICOLAS LE ROUX, Les guerres de religion, Paris, PUF, 2016, «Que sais-je?», 128 pp.

1 Il volumetto, pubblicato di recente da Nicolas Le Roux, storico esperto di Rinascimento francese, pur proponendo una sintesi di ricerche decisamente più ampie, condotte in precedenza dall'A., ha il merito di fornire un quadro chiaro e puntuale dei momenti più rilevanti all'interno delle guerre di religione, per un periodo che viene considerato a partire dal 1520 circa, quando cioè in Francia comincia a diffondersi e a far discutere la teologia luterana, fino all'assassinio di Henri III nel 1589. In particolare Le Roux ritraccia gli avvenimenti salienti di quei quarant'anni che spaccano letteralmente la Francia in una divisione confessionale senza precedenti, divisione cruenta che porta sia i cattolici sia i protestanti a trasformare, come noto, delicati questioni di spiritualità in un vero e proprio laboratorio politico e di propaganda politica. Passando attraverso alcune analisi relative al celebre massacro della Saint-Barthélemy (1572), Le Roux ricorda giustamente una data cruciale nel panorama delle divisioni scismatiche rinascimentali; egli sottolinea cioè il ruolo determinante per le guerre di religione dell'anno 1574, anno in cui, con la quinta guerra, le frontiere confessionali fra cattolici e protestanti paiono offuscarsi e indebolirsi rispetto a un preciso riconoscimento di ideologia confessionale generante una certa permeabilità di una teologia rispetto all'altra. Se da un lato si manifesta quindi un problema di interconfessionalità nel riconoscimento di posizioni teologiche nette, dall'altro, il tempo delle guerre di religione, come ricorda Le Roux, diventa momento di grande diffusione di manifesti, trattati politici, pamphlets e testi di contenuto esegetico e teologico che funzionano da strumento ancora attualissimo per ricostruzioni storiche e interpretazioni critiche. Passando quindi in rassegna le tappe fondamentali delle sanguinose opposizioni fra cattolici e protestanti nella Francia del Cinquecento, con una rapida apertura al panorama del primo Seicento, il presente lavoro consegna un'ottima sintesi di 
problematiche complesse che possono essere proposte, proprio per la chiarezza e per la semplificazione metodologica, a un pubblico di accorti studenti universitari. 